\title{
ENTRE DIREITOS E REDUÇÃO DE CUSTOS TRABALHISTAS: A REFORMA TRABALHISTA JUSTIFICADA PELOS REPRESENTANTES EMPRESARIAIS 1 .
}

BETWEEN RIGHTS AND REDUCTION OF LABOUR COSTS: THE LABOUR REFORM JUSTIFICATED BY ENTREPRISE REPRESENTATIVES.

ENTRE DROITS ET RÉDUCTION DES COUTTS DU TRAVAIL: LA REEFORME DU TRAVAIL JUSTIFIÉ PAR LES REPRÉSENTANTS DES ENTREPRISES.

ENTRE DERECHOS Y REDUCCIÓN DE COSTOS LABORALES:

LA REFORMA LABORAL JUSTIFICADA POR LOS

REPRESENTANTES EMPRESARIAIS.

Vinicius Foletto Bevilaqua*

\begin{abstract}
RESUMO: O objetivo do artigo é analisar as justificações dos representantes do setor empresarial brasileiro lançadas à reforma trabalhista de 2017. Para analisar as justificações, o recorte do artigo direciona-se para a esfera legislativa brasileira, especificamente concentrando-se nas audiências públicas realizadas na Câmara dos Deputados. A partir do referencial teórico da teoria das justificações de Boltanski, Chiapello e Thévenot, problematiza-se quais as cités mobilizadas pelos representantes do setor empresarial nos momentos críticos da esfera legislativa com relação à reforma trabalhista? Para a finalidade dessa proposta, a pesquisa se desenvolve com base na análise de documentos, a partir das notas taquigráficas das audiências públicas desdobradas na Câmara dos Deputados. Os registros de uma audiência pública foram analisados. O método de análise é a análise de discurso. Como resultados, identificaram-se que as justificações produzidas pelos representantes do setor empresarial gravitam em torno de discursos políticos como a redução do custo trabalhista, a "flexibilização" de contratos trabalhistas, a autonomia privada coletiva e o afastamento do Estado do processo de negociação coletiva. Conclusivamente, aponta-se que os discursos políticos
\end{abstract}

\footnotetext{
* Mestre em Sociologia e doutorando no Programa de Pós-Graduação em Sociologia da Universidade Federal do Rio Grande do Sul (UFRGS), Porto Alegre, RS, Brasil; E-mail: vbevilaqua@gmail.com $1 \mathrm{O}$ artigo foi elaborado no âmbito da tese de doutoramento, sob a orientação do Prof. Dr. Fernando Coutinho Cotanda da Universidade Federal do Rio Grande do Sul (UFRGS), financiada por uma bolsa de estudos do Programa de Excelência Acadêmica (PROEX) da Coordenação de Aperfeiçoamento de Pessoal de Nível Superior (CAPES). Agradecimentos especiais a Rodrigo Hinz da Silva e Marciele Vasconcellos.
} 
dos representantes do setor empresarial perpassam, principalmente, a cité mercantil e, secundariamente, a cité industrial, evidenciando que as justificações mobilizadas mascaram interesses particulares dos representantes do setor empresarial.

Palavras chave: teoria das justificações; esfera legislativa; reforma trabalhista; representantes do setor empresarial; relações trabalhistas.

ABSTRACT: The purpose of the article is to analyse the justifications from representatives of Brazilian entrepreneurial sector launched at 2017's labor reform. To analyse the justifications, the article's cutout is directioned to legislative sphere, specifically aiming to public hearings realized in Chamber of Deputies. From the theoretical framework of the theory of justifications by Boltanski, Chiappelo and Thévenot, it's problematized what are the cités mobilized by the representatives of entrepreneurial sector in critical moments of legislative sphere with relation to labour reform? For the purpose of this article, the research is developed based on the analysis of documents, from the shorthand notes of public hearings deployed in the Chamber of Deputies. Records of a public hearing were analyzed. The method of analysis is discourse analysis. As results, it was identified that the justifications produced by representatives of the entrepreneurial sector gravitate around political discourses such as the reduction of labor costs, the "flexibilization" of labor contracts, collective private autonomy and the withdrawal of the State from the process of collective bargaining. Conclusively, it's pointed out that the political discourses of the representatives of the entrepreneurial sector pass through, mainly, the mercantile cité and, secondarily, the industrial cité, evidencing that the justifications mobilized mask the private interests of the representatives of the entrepreneurial sector.

Keywords: Theory of justifications; Legislative sphere; Labor reform; Representatives of entrepreneurial sector; Labor relations.

$\boldsymbol{R} \boldsymbol{E} \boldsymbol{S U M E}:$ Le objectif de cet article est d'analyser les justifications des représentants du secteur des entreprises brésiliennes lancées à la réforme du travail de 2017. Pour analyser les justifications, la coupure de l'article est dirigée vers la sphère législative brésilienne, en se concentrant spécifiquement sur les audiences publiques tenues à la Chambre des Députés. Du cadre théorique de la théorie des justifications de Boltanski, Chiapello et Thévenot, quels sont les cités mobilisés par les représentants du secteur des entreprises dans les moments critiques de la sphère législative par rapport à la réforme du travail? Aux fins de cette proposition, la recherche est développée sur la base de l'analyse de documents, à partir des notes sténographiques des audiences publiques déployées 
à la Chambre des députés. Les documents d'une audience publique ont été analysés. La méthode d'analyse est l'analyse du discours. Comme résultats, ont été identifiés que les justifications produites par les représentants du secteur des entreprises gravitent autour de discours politiques tels que la réduction des coûts de main-d'ouvre, la «flexibilisation» des contrats de travail, l'autonomie privée collective et le retrait de l'Etat de la négociation collective. En conclusion, il est souligné que les discours politiques des représentants du secteur des entreprises passent, principalement, la cité marchande et, accessoirement, la cité industrielle, attestant que les justifications mobilisées masquent les intérêts privés des représentants du secteur des entreprises.

Mots-clés: Théorie des justifications; Sphère législative; Reforme du travail; Représentants du secteur des entreprises; Relations de travail.

RESUMEN: El objetivo del artículo es analizar las justificaciones de los representantes del sector empresarial brasileño lanzadas a la reforma laboral de 2017. Para analizar las justificaciones, el recorte del artículo se dirige hacia la esfera legislativa brasileña, especificamente concentrándose en las audiencias públicas realizadas en la audiencia pública Camara de los Diputados. A partir del referencial teórico de la teoría de las justificaciones de Boltanski, Chiapello y Thévenot, se problematiza cuáles los citados movilizados por los representantes del sector empresarial en los momentos críticos de la esfera legislativa con relación a la reforma laboral? Para la finalidad de esta propuesta, la investigación se desarrolla con base en el análisis de documentos, a partir de las notas taquigráficas de las audiencias públicas desplegadas en la Cámara de Diputados. Se analizaron los registros de una audiencia pública. El método de análisis es el análisis de discurso. Como resultados, se identificaron que las justificaciones producidas por los representantes del sector empresarial gravitan en torno a discursos políticos como la reducción del costo laboral, la "flexibilización" de contratos laborales, la autonomía privada colectiva y el alejamiento del Estado del proceso de negociación colectiva . En conclusión, se señala que los discursos políticos de los representantes del sector empresarial atravesan principalmente la cité mercantil y, secundariamente, la cité industrial, evidenciando que las justificaciones movilizadas enmascaran intereses particulares de los representantes del sector empresarial.

Palabras clave: Teoria de las justificaciones; Esfera legislativa; Reforma laboral; Representantes del sector empresarial; Relaciones laborales. 


\section{INTRODUÇÃO}

O mundo do trabalho é atravessado por forças sociais interessadas em orientar os caminhos a serem percorridos nas relações trabalhistas. Num contexto planetário, as relações trabalhistas são marcadas por conflitos e disputas sociais. Pode-se compreendê-las por distintos aspectos e ângulos do social. As relações trabalhistas historicamente são marcadas por conflitos outrora abertos, se for pensado as greves, outrora fechados, na esfera legislativa, por exemplo. Inclusive, os mecanismos sociais de absorção desses conflitos e disputas são inúmeros. Aos intentos do artigo, pensa-se a esfera legislativa como um recorte em que se é possível analisar o conflito trabalhista entre distintas forças sociais. Sua intensificação ou sua radicalização dependem, em parte, do contexto político e econômico de determinada formação social. Nesse sentido, a recente crise política e econômica, após a ruptura institucional ${ }^{2}$, agravou um quadro do trabalho que já se apresentava precário e precarizado, informal e excludente. No bojo da instabilidade política e econômica, algumas medidas foram operadas para produzir transformações no mercado de trabalho, nas relações trabalhistas e na forma legal em que o Estado abarca o conjunto da classe trabalhadora. Dentre as medidas, foi concretizada uma proposta de mudança drástica na legislação trabalhista. Os esforços deste artigo pretendem debruçar-se sobre essa questão.

A reforma trabalhista, eleita como o objeto de estudo, apresenta características marcantes que a conectam ao cenário contemporâneo. Para percorrer esse caminho, torna-se necessário o exame mais detido dos discursos e das justificações mobilizadas pelos agentes sociais interessados e favoráveis ao conteúdo da reforma trabalhista. Portanto, a partir de uma leitura preliminar dos dados coletados por meio das notas taquigráficas das audiências públicas ${ }^{3}$

2 A ruptura institucional, compreendida como o processo de impeachment produzido sobre a ex-presidenta Dilma Rousseff em 2014, foi um processo institucional conturbado onde os poderes Executivo e Legislativo entraram em rota de colisão.

3 Audiências públicas são momentos em que o Congresso Nacional, seja a Câmara dos Deputados ou o Senado Federal, convida membros da sociedade para lançarem argumentos e opiniões sobre determinada legislação a ser alterada. São momentos particulares do processo de discussão e debate das legislações onde membros da sociedade civil podem contribuir, sejam "especialistas" em determinado tema ou representantes de setores da sociedade diretamente afetados pela legislação debatida. 
em torno da proposta de lei, elegeram-se os representantes do setor empresarial brasileiro. Inclusive, os representantes do setor empresarial que se manifestaram nas audiências públicas mostraram-se, em absoluto, adeptos das mudanças propostas pela reforma.

$\mathrm{O}$ artigo não pretende esgotar o objeto de estudo analisado, entretanto, busca ampliar a discussão em torno das modificações recentes nas relações trabalhistas do caso brasileiro. Para tal, recorrerse-á à teoria das justificações de Boltanski, Thévenot e Chiappelo com a expectativa de refletir sobre quais as justificações mobilizadas pelos representantes do setor empresarial brasileiro. Para identificar e analisar as justificações, resgata-se o conceito de cité proposto por Boltanski e Thévenot na obra De la justification.

Metodologicamente, os dados foram organizados e categorizados com o auxílio do software informacional Nvivo 11. Uma audiência pública, ocorrida na Câmara dos Deputados, foi categorizada e analisada em sua integralidade, isto é, no que se refere as falas dos representantes do setor empresarial. Destaca-se que a audiência pública investigada teve como principais convidados os representantes do setor empresarial, o que propiciou um material empírico amplo para análise das justificações mobilizadas, com relação à reforma trabalhista.

A sociologia operada no artigo se define, epistemologicamente, por duas dimensões. A primeira orienta a leitura a partir de um ponto de encontro entre uma sociologia da crítica e uma sociologia crítica. A sociologia da crítica aparece a partir da incorporação teórica do pragmatismo francês de matriz boltanskiana, principalmente, e a partir das contribuições de Thévenot e Chiappelo, desaguando na teoria das justificações que engloba os apoios normativos mobilizados em momentos críticos, ou seja, as cités e os modelos de justiça que são manifestados. A leitura proposta, nesse sentido, é por um lado heterodoxa, tomando os conceitos da teoria das justificações não como acabados ou intocáveis, mas em constante diálogo com o empírico e demonstrando seu valor heurístico na medida em que consegue fazer refletir o olhar sociológico na interface dos dados. Por outro lado, a segunda dimensão epistemológica torna operacional a sociologia crítica que se manifesta no artigo por meio do argumento 
de que o pesquisador, conforme recorda Chiappelo (2003), expressa suas próprias fundações normativas implicitamente na escrita. Não se propõe no artigo uma sociologia "neutra", e sim uma sociologia crítica, fundamentalmente, pois a própria sociologia é produto da sociedade e, nesse sentido, traz consigo as inquietações produzidas em outros níveis, ainda que reflexiva e cientificamente orientada.

O material empírico analisado funciona para sustentar o argumento do artigo, o qual é resumido na compreensão de que as justificações mobilizadas pelos representantes do setor empresarial ganham sentido quando os próprios atribuem, principalmente, uma lógica mercantil, isto é, um modelo de justiça orientado pela cité mercantil, na qual as justificações favoráveis à reforma trabalhista são fundamentadas em noções como custo do trabalho, negociar livremente as relações trabalhistas sem interferência do Estado e a "flexibilização" dos contratos de trabalho. Em especial, destaca-se que as justificações mobilizadas mascaram os interesses dos agentes empresariais quando pensada a reforma trabalhista. Pontualmente, os representantes do setor empresarial mobilizam também apoios normativos orientados pela lógica industrial e cívica, especificamente, as cités industrial e a cité cívica.

$\mathrm{Na}$ próxima secção, apresentar-se-á, ligeiramente, o panode-fundo do artigo, junto dos assuntos diretamente relacionados ao contexto político, econômico, legal e social da reforma trabalhista.

\section{A QUESTÃO SOCIAL DA PROTEÇÃO SOCIAL AO TRABALHO}

A questão social exposta depende da formação social considerada. A configuração das questões sociais torna-se condicionada por processos que incluem e refletem distintas características históricas e sociais das sociedades em análise. $\mathrm{O}$ trabalho, enquanto um suporte crucial à inscrição numa dada estrutura social, conforme Castel (1998), enseja uma disputa por forças sociais interessadas no seu controle e regulação. Produto de um conjunto de conflitos e disputas principalmente, mas também de acordos e consensos, o trabalho transforma-se. A proteção social, portanto, surge como resultado 
de processos semelhantes àqueles que definem e regulam o trabalho.

Se Marx (2012), por um lado, dissertava sobre a luta de classes na França de 1848-1850 e a reivindicação proletária ao droit au travail, esnobado pelas classes burguesas republicanas e burguesas monárquicas, Castel (1998), por outro, atentava à crescente pauperização da condição de existência da classe trabalhadora francesa. Na América Latina, a consolidação da proteção social moderna conhece um conjunto de processos socioculturais distintos ${ }^{4}$. A questão social latino-americana, conforme afirma Wanderley (2013, p. 66), “imposta pelos colonizadores por meio do pacto colonial, e (...) dirigida pelo pacto de dominação burguesa", marcadamente interfere na produção social da proteção ao trabalho. Planetária, a implantação e modificação da proteção social moderna, central ou periférica, exige recorrentemente o engajamento das forças sociais interessadas em influenciar seus rumos. Tardiamente com relação aos países europeus, o Brasil, um dos últimos na esteira do processo de abolição da escravidão no Ocidente, efetua progressivamente uma proteção social na área do trabalho na primeira metade do século XX, em especial nas décadas de 30 e 40.

A elaboração da Consolidação das Leis do Trabalho (CLT), em 1943, representa um momento crucial na história da legislação trabalhista brasileira onde se torna visível o conjunto dos interesses ${ }^{5}$ do Estado na proteção social. Constituindo-se enquanto um conjunto de normas e regras de uso do trabalho que estendiam a proteção do Estado à classe trabalhadora, a CLT fora produzida num contexto onde, conforme Cardoso e Lage (2006), o Estado, e não os trabalhadores, era o espaço legítimo de formação do interesse coletivo. A classe trabalhadora $^{6}$, mesmo ativamente lutando pela reivindicação de seus direitos na sociedade civil, acabou não participando diretamente do processo que elege e fortifica seus próprios direitos, transformando-se em coad-

4 No caso brasileiro, a título de exemplo histórico, a formulação da Constituição de 1824, para fundamentar simbolicamente o Brasil-Império, esbarrou a elaboração da proteção social no conceito de cidadania. Com fim de não abalar a estrutura escravocrata brasileira, o conceito de cidadania, conforme recorda Santos e Ferreira (2014), precisou legitimar e diferenciar os membros da sociedade em duas categorias: homens livres, os cidadãos, e homens não livres, isto é, escravos.

5 Diz-se "o conjunto dos interesses" porque eram vários os interesses do Estado em tal Lei. Além do ganho social do governo, por meio da propaganda, com a população, paralelamente Getúlio Vargas e os demais grupos envolvidos no planejamento político-econômico procuravam sinalizar positivamente aos empresários e ao capital estrangeiro o ímpeto industrialista dos esforços governistas. 6 Cabe destacar que a classe trabalhadora não é compreendida enquanto um todo homogêneo e orgânico. A classe trabalhadora é composta por diferentes tipos de trabalhadores, identidades, práticas e crenças. 
juvantes num processo centralizador e unificador protagonizado pelo Estado ${ }^{7}$. A partir do momento em que o Estado toma para si a formação do interesse coletivo dos trabalhadores e o transforma em legislação trabalhista, o próprio conflito de interesses, outrora aberto na sociedade civil, transfere-se à esfera do direito do trabalho (Cardoso \& Lage, 2006). O protagonismo do Estado na legislação trabalhista também significou um aceno ao mercado brasileiro, em especial ao setor industrial, com o propósito de galvanizar o desenvolvimento industrial, um dos principais nortes da política econômica de Getúlio Vargas, conhecida como o processo de modernização nacional ${ }^{8}$. Por outro lado, uma parte expressiva do setor patronal, conforme lembra Roxborough (2009), atacou ferozmente a CLT para proteger e controlar simultaneamente o trabalho. Ao delimitar os usos do trabalho e a própria organização dele, voltando-se à industrialização nacional, o denominado "Estado Novo" conseguiu irritar setores patronais não contemplados pelo processo.

As regras trabalhistas cristalizadas na forma da CLT da década de 40 não significaram um engessamento dos seus artigos e parágrafos. Pelo contrário, desde a sua fundação a CLT sofreu inúmeros processos de alterações no seu conteúdo ${ }^{9}$. As mudanças históricas, sofridas pela CLT, têm como causa as lutas travadas no centro da sociedade pelas forças sociais interessadas em transformar suas ideias e visões de mundo em leis. O exemplo histórico da CLT possibilita percorrer a proteção social moderna como, historica e socialmente, produzida por uma gama de agentes e grupos sociais interessados. Parte da produção localiza-se no bojo da dinâmica produzida e reproduzida na esfera legislativa. Se a esfera legislativa for concebida enquanto o espaço social de produção, reprodução ${ }^{10}$ e legitimação

7 De acordo com Antunes e Carvalho (2008), o sindicalismo brasileiro da década de 30 fora amarrado por um Estado centralizador cujo uma das principais interfaces com o setor trabalhista era o controle das atividades sindicais pelo Estado a partir da legislação. Roxborough (2009) resgata também que a baixa frequência das greves, resultado de um Estado controlador, a proibição da formação de confederações nacionais de trabalhadores e a supressão efetiva das lideranças trabalhistas de esquerda e independentes inviabilizaram qualquer tipo de contraposição, autonomia e iniciativa ao corpo da classe trabalhadora.

8 Como destaca Love (2011), a abertura de bancos de desenvolvimento industrial e mudanças na estrutura tarifária brasileira são medidas políticas representativas do interesse do Estado da década de 1930 e 1940 em fomentar e produzir respostas à classe patronal empresarial, em específico o setor industrial. 9 Em virtude do artigo não se envolver diretamente com as alterações de conteúdo técnico da CLT como a disciplina do Direito Trabalhista se interessaria e, por outro lado, exigir um esforço intelectual que excede as condições de exposição no artigo, o tópico não será abordado.

10 Compreende-se a esfera legislativa como um espaço social de produção, mas também de repro- 
de leis via dissenso consensual, pode-se explorar a esfera legislativa como um lugar da sociedade com potencial de contribuir para uma melhor compreensão sociológica acerca da proteção social. Nesse sentido, as modificações propostas à CLT, que ganham denominações públicas genéricas de tempos em tempos como "reformas trabalhistas", permitem a identificação de um objeto de estudo significativo e relevante aos intentos do artigo.

As pesquisas e estudos relacionados com as reformas trabalhistas abordam principalmente três assuntos: a) pesquisas do caráter técnico das regras a serem modificadas pela reforma ${ }^{11}$; b) os efeitos das reformas quando implementadas ${ }^{12}$; e c) o processo de legitimação política das reformas ${ }^{13}$. No primeiro item, os estudos se encarregam da análise do conteúdo técnico, voltado ao Direito do trabalho, da correlação das mudanças propostas com a Constituição dos países analisados, da lógica interna e do papel protetivo das modificações quando prospectivamente pensadas com as relações trabalhistas. No item $b$, as pesquisas se debruçam sobre os efeitos das mudanças na legislação trabalhista sobre o mercado de trabalho, as relações trabalhistas entre trabalhadores-patrões e as condições de trabalho, como mudanças nas características da segurança do trabalho que algumas modificações nas legislações exigem. Por fim, o último item refere-se às análises concentradas sobre os processos legislativos e políticos que criam ou impedem as transformações nas legislações trabalhistas. O papel do Poder Executivo, a relação entre Executivo-Legislativo, a configuração parlamentar da esfera legislativa ou o encadeamento das agências dos agentes protagonistas das mudanças. Dentro do quadro sintético, o artigo se insere no último item, e propõe uma abordagem teórica e empírica que sublinha a importância analítica dos discursos e justificativas, mobilizados para transformar os interesses em mudanças na legislação trabalhista.

dução, pois segundo pesquisas, como a de Moya (2005), a esfera legislativa brasileira reproduz, no sentido de continuidade, propostas oriundas do Poder Executivo.

11 Os seguintes estudos são exemplos: Galvão (2003), Goldín (2012), Ojeda e Gutiérrez (2012), Sempere (2012).

12 Mayer (2016), Pessanha e Artur (2013), Kaplan (2009), Anner (2008), Tostes e Villavicencio (2012), Burgess (2010). No estudo de Pessanha e Artur (2013) são pesquisas envolvidas com os efeitos das reformas quando implementadas.

13 As pesquisas representativas: Armelino (2015), Diniz (2005), Gibbons (2015), Cook (1998, 2002), Haagh (2002), Taylor (2004), Morris (2006). 
Nesse sentido, a ênfase da análise recai sobre o caráter discursivo e justificativo do processo de modificação da reforma trabalhista implementada em 2017.

Recentemente, a reforma trabalhista proposta pelo Poder Executivo em 2016, com aprovação durante a passagem pelo legislativo e sancionada pelo Poder Executivo em julho de 2017, foi objeto de disputa por diferentes setores da sociedade, como o setor parlamentar, o estatal, o empresarial, o trabalhista, o dos operadores do Direito e dos "especialistas"14. Identificada como Projeto de Lei da Câmara 6.787/16, quando na Câmara dos Deputados, e Projeto de Lei do Senado 38/2017, no Senado Federal ${ }^{15}$, a reforma trabalhista analisada teve três pilares alvo de mudança, os quais foram: as condições de trabalho, a organização sindical e a negociação coletiva ${ }^{16}$. As ideias que atualizaram a proposta da reforma são discutidas desde a década de 1990 pelos diferentes setores da sociedade interessados, em especial o setor parlamentar, o empresarial e o trabalhista. Há um forte interesse nas modificações propostas pela última reforma trabalhista por um período, no mínimo, de três décadas.

O setor empresarial apoia um conteúdo, presente na reforma trabalhista, cujo interesse remete à década de 1990, e desde então enfrenta resistências à implementação por parte do setor trabalhista, em especial dos sindicatos, e uma parte menor do setor parlamentar, se for pensado a esfera legislativa a nível federal. Por um lado, essas ideias são fundamentadas em orientações normativas inspiradas em princípios econômicos que remetem a autores como Adam Smith (1723-1790), David Ricardo (1772-1823), Friedrich Hayek (18991992) e Milton Friedman (1912-2006), como a flexibilização dos contratos de trabalho, a livre circulação de mercadorias e o exercício pleno da liberdade individual. Por outro, as ideias ganham força dentro de condições favoráveis a sua implementação. Nos últimos

14 Cada um desses setores opera com uma lógica própria que eventualmente pode se aliar uma com a outra, como poderiam ser pensados os momentos da formação de coalizões que defendam determinadas ideias ou valores.

15 A partir deste momento, as referências legislativas PLC 6.787/16 e PLS 38/2017, junto a todo conteúdo que transitou pela esfera legislativa, serão agrupadas em torno da noção de "Reforma trabalhista". As situações em que o que se é discutido escapa à definição proposta serão sinalizadas. 16 Algumas modificações foram discutidas desde a década de 90 no Brasil, conteúdos que envolvem desde a flexibilização contratual nas relações trabalhistas até a capacidade de negociação entre empregador e empregado sem a interferência do Estado. 
anos, após o processo imposto de ruptura institucional em 2016, o número de parlamentares que resistiam às investidas daquelas ideias econômicas, levantadas tanto por membros internos do parlamento brasileiro quanto pelo setor empresarial como um todo, diminuiu e, com isso, permitiu um terreno para sua implementação. Entretanto, destaca-se que ideias não são automaticamente traduzidas em leis e modificações na legislação por meio de condições favoráveis apenas, pois dependem de todo um processo concatenado de eventos, agências e discursos. O artigo apresentado se encarrega de explorar e examinar a parte discursiva do processo, em específico atentando para as justificações sustentadas por apoios normativos mobilizados pelos representantes do setor empresarial, em audiências públicas na Câmara dos Deputados.

Para que os diferentes setores da sociedade possam transformar suas ideias e valores em efetiva mudança na legislação trabalhista, necessita-se expor um conjunto de justificações, sustentadas por apoios normativos, que qualifiquem e legitimem o que está presente no discurso público. Vencer disputas ou conflitos nas sociedades vai além da dimensão material dos diferentes setores envolvidos, pois também se torna necessário legitimar simbolicamente o que está sendo proposto ao grande público. Não basta possuir uma vasta quantidade de recursos materiais como dinheiro ou bens pessoais, para convencer o grande público necessita-se da capacidade simbólica que se produz na dimensão discursiva que é operada por meio das forças sociais. A próxima secção se encarrega de expor as ferramentas teórico-metodológicas empregadas para análise pretendida.

\section{DA TEORIA DAS JUSTIFICAÇÕES À DISCUSSÃO METO- DOLÓGICA}

O conceito de justificação está no centro da teorização pretendida no artigo. Fundamentado a partir de Boltanski, Thévenot e Chiapello, o conceito de justificação vai além de uma visão particular ou pessoal de mundo. As justificações não são produzidas exclusivamente da particularidade de cada agente, mas também são pro- 
dutos de forças sociais que perpassam e atravessam as sociedades e seus membros, a todo momento. Descrever e analisar as justificações possibilita o acesso ao conteúdo dessas forças sociais. As diferentes forças sociais que exercem influência na sociedade necessitam não somente do aparato material, mas especialmente da conquista dos corações e mentes por meio da dimensão simbólica que legitime o que está sendo proposto ${ }^{17}$. Nesse sentido, as justificações cumprem um papel de legitimar o interesse ou desejo dos diferentes agentes.

A busca pelas justificações permite apreender os tipos de argumentos que legitimam a importância do que se é discutido e que têm por base diferentes tipos de bem comum e ordens de grandeza. Os diferentes tipos de justificação procuram legitimar reivindicações e afirmações de mundo que são generalizáveis e relevantes, sustentadas por visões de bem comum e modelos de justiça.

As justificações são informadas pelas cités. Cités ou "cidades" são modelos de justiça que informam disputas em torno do que é justo e injusto no mundo social. Nos estudos de Boltanski e Chiapello (2009) e Boltanski e Thevenot (2006), os autores identificaram a existência de sete cités18: mercantil, industrial, doméstica, cívica, da fama, inspiradora e de projetos. Cada uma das cités possui regimes de justificação próprios. Os agentes, ao justificarem suas ações e ideias, apoiam-se em argumentos que representam as características das cités. Neste sentido, interessa analisar quais os apoios normativos, isto é, as fontes de justificação que cada agente representante do setor empresarial brasileiro lança nos contextos de disputa das audiências públicas na esfera legislativa federal.

Os modelos de justiça incorporados no conceito de cité sintetizam-se em sete tipos de modos de avaliação da grandeza de determinado sujeito ou objeto. A cité mercantil baseia-se no princípio do custo, a industrial no da eficiência técnica, a cívica no bem-estar coletivo, a doméstica na reputação, a inspirada na criatividade, a da opinião na fama e a de projetos na capacidade conectiva. Cada uma

17 Conforme Bourdieu argumenta na sua obra Sobre o Estado, para o Estado exercer o controle, por exemplo, não basta ter o monopólio da violência física, como dizia Weber, mas também necessita do monopólio da violência simbólica.

18 Existiria ainda uma cité ecológica, a qual vincula justificações voltadas ao ambientalismo, conforme estudo de Thévenot, Moody e Lafaye (2000). 
das formas destacadas apresenta-se como um princípio de avaliação e classificação dos seres (sujeitos e objetos), que se tornam, à luz daquelas, grandes ou pequenos. Os princípios de classificação, nesse sentido, seriam características de qualquer sociedade. Em relação com o objeto de estudo aqui apresentado, as formas de classificação funcionam para identificar, nos discursos dos representantes do setor empresarial, quais os modelos de justiça mobilizados para avaliar e classificar a grandeza ou pequenez da reforma trabalhista.

As justificações de Boltanski e Thévenot (2006) analiticamente são observadas nos momentos críticos. Os autores franceses argumentam que os agentes, nos momentos críticos, isto é, em momentos de disputa entre diferentes visões de mundo, lançam mão de justificativas para afirmar e legitimar sua posição frente ao conflito e ganhar uma disputa ou alcançar o consenso. Ao se concentrar, neste artigo, nas audiências públicas sobre a reforma trabalhista que ocorrem na esfera legislativa, cabe indicar que, em si mesmas, podem ser consideradas diferentes momentos críticos que se manifestam ao longo dos debates no Congresso Nacional. O interesse reside na compreensão da dinâmica no polo do conflito. Isto é, como os diferentes agentes mobilizam, em situações de conflito, justificações e qual a grandeza dos argumentos.

A operacionalização do conceito de cité necessitou a revisão da teoria da justificação a partir das principais obras que propõem o estudo das justificações. Na obra On justification, de Boltanski e Thévenot (2006), tem-se a explanação do framework de análise dos sociólogos para a construção das tipologias deduzidas do conceito de cité. Na obra $O$ novo espírito do capitalismo, de Boltanski e Chiappelo (2009), tem-se a demonstração das cités quando voltadas à compreensão das justificações e críticas inscritas no capitalismo contemporâneo. Da leitura compreensiva das duas obras foi possível a elaboração de um quadro de operacionalização do conceito de cité. 
Tabela 1 - Operacionalização do conceito de cité

\begin{tabular}{|c|c|c|}
\hline Conceito & Componentes & Descritores \\
\hline \multirow[t]{13}{*}{ Cité } & $\begin{array}{l}\text { Princípio superior } \\
\text { comum }\end{array}$ & $\begin{array}{l}\text { Princípios que julgam ações, coisas e } \\
\text { pessoas }\end{array}$ \\
\hline & Estado de grandeza & $\begin{array}{l}\text { Seres grandes que funcionam como re- } \\
\text { ferência para coordenação }\end{array}$ \\
\hline & $\begin{array}{l}\text { Estado de pequenez e } \\
\text { declínio da cité }\end{array}$ & \begin{tabular}{|l|}
$\begin{array}{l}\text { Identificação dos pequenos no argumen- } \\
\text { to da justificação }\end{array}$ \\
\end{tabular} \\
\hline & Dignidade humana & $\begin{array}{l}\text { Capacidade "natural" para funcionar a } \\
\text { serviço do bem comum }\end{array}$ \\
\hline & Repertório de sujeitos & Sujeitos relevantes à justificação \\
\hline & $\begin{array}{l}\text { Repertório de objetos e } \\
\text { dispositivos }\end{array}$ & Objetos relevantes à justificação \\
\hline & Fórmula de investimento & Sacrifícios para ascender à grandeza \\
\hline & Relação de grandeza & Relação entre grandes e pequenos \\
\hline & $\begin{array}{l}\text { Relações naturais entre } \\
\text { os seres }\end{array}$ & $\begin{array}{l}\text { Verbos que designam relações entre seres } \\
\text { Relação de ordem entre os seres }\end{array}$ \\
\hline & $\begin{array}{l}\text { Figuras harmoniosas da } \\
\text { ordem natural }\end{array}$ & $\begin{array}{l}\text { Figuras representativas das relações en- } \\
\text { tre os seres }\end{array}$ \\
\hline & Testes modelo & $\begin{array}{l}\text { Situações de interação que desafiam a } \\
\text { grandeza dos seres }\end{array}$ \\
\hline & $\begin{array}{l}\text { Modo de expressão de } \\
\text { julgamento }\end{array}$ & $\begin{array}{l}\text { Forma na qual se manifesta o princípio } \\
\text { superior comum }\end{array}$ \\
\hline & Forma de evidência & $\begin{array}{l}\text { Forma na qual a evidência é apresentada } \\
\text { por meio do discurso }\end{array}$ \\
\hline
\end{tabular}

Fonte: quadro elaborado pelo autor e produzido a partir de Boltanski e Thévenot (2006) e Boltanski e Chiappelo (2009).

Cada um dos componentes do conceito de cité busca apreender uma parte da realidade, ainda que condicionada pelo próprio conceito. Pelo elevado grau de abstração do conceito, os componentes, durante o processo de operacionalização, que encaixa o conceito, teórico, com a realidade, empírica, foram conectados aos descritores que funcionam na interface com o objeto de estudo, isto é, com as justificações sobre a reforma trabalhista. Nesse sentido, cada operacionalização deve arcar com as exigências empíricas do objeto de estudo. Os conceitos respondem parcialmente à realidade, devendo o pesquisador buscar a elaboração de pontes operacionais, isto é, níveis de abstração encarados como dimensões, componentes e descritores (ou indicadores) que englobem simultânea e reflexivamente o teórico e o empírico.

Os procedimentos de investigação concentram-se em métodos e técnicas que garantam a produção e análise de dados qualitativos. Para a produção dos dados, recorreu-se à coleta de documentos. 
Os documentos analisados referem-se às notas taquigráficas produzidas pela Câmara dos Deputados. Cada audiência pública, plenária e comissões têm suas sessões registradas na forma de notas taquigráficas. Foi selecionada uma audiência pública na qual os representantes do setor empresarial ${ }^{19}$ encontravam-se presentes. Na audiência pública teve seis representantes do setor empresarial: Confederação Nacional da Indústria (CNI), Confederação Nacional das Finanças (CNF), Federação Brasileira dos Bancos (FEBRABAN), Confederação Nacional da Agricultura (CNA), Confederação Nacional da Saúde (CNS) e Confederação Nacional do Transporte (CNT). A escolha por uma audiência pública reflete a relevância dos representantes do setor empresarial. São confederações importantes do setor empresarial brasileiro que representam uma grande gama de agentes empresariais e, portanto, seus discursos ganham relevância ${ }^{20}$.

Para analisar os dados, recorreu-se ao método da análise de discurso ${ }^{21}$. A análise de discurso favorece o objetivo geral do artigo, em virtude de ser orientado para "as condições de produção do texto, dos sentidos que ele produz e da forma como tais sentidos são gerados" (Almeida, 2014, p. 145). Embora o artigo se volte para as justificações, é imprescindível atentar que estas são atravessadas por uma ampla gama de sentidos onde cabe à análise de discurso distinguir e organizar as possibilidades compreensivas. Analisar as justificações requer delimitar os sentidos implícitos ao discurso. Resgatando Gill (2002), quatro são as características da análise de discurso que conferem capacidade analítica às justificações: a) uma postura crítica frente ao conhecimento dado como "natural" e "neutro"; b) o entendimento de que discursos e, no caso, justificações, são produtos de determinados contextos históricos e culturais; c) o reconhecimento dos discursos e do conhecimento como construções sociais;

19 Por "representantes do setor empresarial" compreendem-se as federações regionais, confederações nacionais e demais sindicatos patronais. O termo "empresarial" destina-se à qualquer atividade econômica patronal relacionada aos setores industrial, comercial, de transportes, de saúde, agrícola e bancário.

20 Destaca-se que existe um gap entre representação de crenças empresariais e as próprias crenças dos empresários representados pelas confederações. Ciente de tal distancia na representação, o artigo insiste em referenciar os agentes empíricos enquanto representantes do setor empresarial, e, mesmo que muitos sejam empresários, evitar classifica-los como uma "média dos interesses empresariais". 21 Destaca-se que a análise de discurso se divide em diferentes escolas de análise. Nesse sentido, a pesquisa não se debruçou exclusivamente sobre uma escola específica, e sim propôs abarcar um conjunto de atitudes inscritas de modo geral nas correntes teóricas da análise de discurso. 
e d) a observação de que os discursos são conectados às práticas. $\mathrm{O}$ discurso político assume, nos interesses do artigo, uma centralidade analítica significativa. Seguindo Pinto (2006), o discurso político se manifesta cotidianamente e, especialmente, expressa-se plenamente nos espaços políticos próprios, como assembleias legislativas, plenárias ou comissões de discussão de leis. No caso da reforma trabalhista, as audiências públicas caracterizam-se como um espaço da prática política onde diferentes agentes da sociedade civil, representantes do setor empresarial, do setor trabalhista, e os próprios parlamentares, manifestam-se enquanto agentes sociais politicamente orientados ${ }^{22}$.

A análise de discurso apresenta uma aproximação com a teoria das justificações de Boltanski, Thévenot e Chiappelo. Se na teoria das justificações é inescapável a identificação das justificações lançadas pelos agentes em momentos críticos; e na análise de discurso ocorre o interesse na compreensão de como os agentes discursam sobre ideias, valores e visões, cabe ao pesquisador, frente ao objeto de estudo, produzir uma análise que registre como os agentes sociais, em momentos de disputa, mobilizam um conjunto de justificações que sustentam ideias, valores e visões de mundo social e historicamente produzidos.

Os dados apresentados foram codificados com o auxílio do software de análise qualitativa Nvivo 11. O software possibilita a organização, sistematização e descrição de dados qualitativos a partir da inclusão de documentos digitalizados (no formato word, $p d f$ e outros). Nesse sentido, o corpus de documentos gerado a partir da audiência pública analisada foi incluído no programa, para posterior organização, codificação e descrição dos dados.

22 Enfatiza-se "politicamente orientados" em virtude de os agentes, em geral, se apresentarem como "especialistas", apenas interessados em contribuir com uma análise "técnica" das alterações legislativas debatidas. Atenta-se ao equívoco de se expressar enquanto um "especialista" que é "neutro", pois mascara a ideologia implícita em qualquer discurso. A análise de discurso francesa, inclusive, desde suas raízes em Michel Pêcheux, defende a ideia de que qualquer discurso é atravessado por ideologias. 


\section{OS DISCURSOS E APOIOS NORMATIVOS DOS REPRE- SENTANTES DO SETOR EMPRESARIAL}

A análise da audiência pública com representantes do setor empresarial suscitou reflexões sobre a reforma trabalhista e os apoios normativos mobilizados pelos agentes empresariais. A exposição da análise busca a citação direta do material analisado para que o leitor possa, pelos meios auxiliares apresentados e a partir de seu próprio entendimento, compreender o caminho lógico percorrido pela pesquisa.

Do material empírico, foram selecionados para demonstração do argumento sete trechos dos discursos dos representantes do setor empresarial. Em virtude da natureza da pesquisa ser qualitativa e dos discursos expostos representarem, a nível nacional, os representantes legítimos dos agentes empresariais, considera-se adequado explorar o espectro de visões de mundo, valores e ideias associadas ao mundo do trabalho e, em específico, ao mundo empresarial.

Os representantes do setor empresarial, em termos gerais, mobilizam em seus discursos elementos para justificar o avanço da reforma trabalhista. Os trechos destacados ao leitor do artigo referem-se às passagens que evidenciam dimensões e ângulos diferentes e complementares, se for imaginado um discurso síntese, das justificações dos agentes empresariais. O primeiro trecho destacado refere-se à relação entre a legislação trabalhista e a geração de empregos.

O Brasil, nesse momento, está prestes a ter um dado muito ruim. Nós caminhamos para 14 milhões de desempregados, número que choca, número forte. Além disso, muitos dos problemas do desemprego, a meu ver, têm a ver com uma lei trabalhista que protege muito o trabalhador, mas, por outro lado, retira dele exatamente o bem maior que ele tem: o emprego.

Representante da CNF e FEBRABAN

O representante da CNF e FEBRABAN mobiliza um dado referente ao desemprego, destaca-o e associa-o à legislação traba- 
lhista, alvo de modificação. Argumenta que a legislação trabalhista "protege muito o trabalhador" e, com isso, acaba retirando o "bem maior" do trabalhador que, ao representante, é o emprego. Na estratégia discursiva, o agente empresarial reifica a legislação trabalhista, como se fosse um ser capaz de agência, e a conecta com a geração de empregos, esse que é um tema caro ao discurso político brasileiro. A forma como a legislação trabalhista é mobilizada, no discurso acima, aponta para esta como um obstáculo aos empregadores, para que possam aumentar a oferta de postos de trabalho. Com a estratégia discursiva, o agente busca conferir à CLT um caráter causal do tipo determinante à geração de empregos, justificando sua modificação.

Os apoios normativos mobilizados no discurso do agente empresarial orientam a compreensão do emprego como um "bem", uma "coisa", uma "posse". Essa compreensão aponta para uma relação de grandeza de agentes e entre si e objetos, que é qualificada a partir da posse. A relação de grandeza de uma cité é a forma na qual os diferentes seres (agentes e objetos) se relacionam com base na grandeza da cité, ou seja, como se opera a relação entre grandes e pequenos. Os grandes e pequenos, no discurso destacado, produzem um vínculo fundado na posse. Os grandes têm muitas posses e muito a oferecer nas trocas de bens, mercadorias e objetos, enquanto os pequenos possuem poucas posses e pouco a oferecer. $\mathrm{O}$ emprego, no discurso, apresenta-se como uma posse importante, se não vital, ao trabalhador. Nesse sentido, os agentes empresariais, na totalidade, favoráveis à reforma trabalhista, buscam justificar seus interesses e suas ideias a partir da mobilização de um apoio normativo fundado na relação de posse de agentes entre si e objetos, com a ótica de que ter posses é imprescindível para o sucesso de qualquer empreitada relacionada ao mundo do trabalho.

No próximo trecho do discurso do representante da CNA, o agente empresarial destaca, na sua observação, que o contexto econômico atual necessita de respostas que acompanhem sua dinâmica e indica que, caso não haja essa resposta, é preciso adotar medidas drásticas como "eliminar emprego". 
O que este projeto traz realmente de novidade e de importância para o cenário econômico? Celeridade. Nós precisamos de algo mais dinâmico para dar respostas. Ivo já deu vários exemplos aqui. De repente, podemos ajustar uma escala, uma jornada, fazer algo de forma mais eficiente. Temos que relembrar quem é o maior fiscal da empresa: o próprio trabalhador. Como bem foi lembrado pelos expositores que me antecederam, o maior direito, Damião, como você bem disse, é o direito ao emprego. E hoje o que está em xeque é modular alguma coisa ou adotar na minha empresa uma posição radical, ou seja, eliminar emprego. É isso que está em jogo.

Representante da CNA

Implicitamente, o agente empresarial atende a uma formação discursiva associada a ideias econômicas voltadas para a flexibilização de contratos de trabalho. Em épocas de crise política e econômica, que, dentre de várias dimensões, reduzem a taxa de lucro das empresas, os agentes empresariais e as empresas de grande porte geralmente adotam explicitamente "cortes dos custos de manutenção", o que invariavelmente acarreta na demissão em massa de trabalhadores. No encadeamento dos discursos, ver-se-á que os representantes do setor empresarial justificam parte da importância da reforma trabalhista para conseguir reduzir custos associados a CLT. Reduzir o custo contratual encaixa-se num interesse mais profundo que é a redução dos custos trabalhistas como um todo. A "celeridade", nesse sentido, atende a um requisito normativo econômico associado à flexibilização de contratos de trabalho, isto é, na prática, optar por uma (des)regulação das jornadas, escalas e no trecho "fazer algo de forma mais eficiente", por sua abrangência e indefinição, pode-se encaixar, inclusive, contratações e demissões que atendam aos requisitos da flexibilização contratual da classe trabalhadora.

No aspecto metodológico, conceitual e operacional da análise, têm-se a observação dos descritores "princípios que julgam ações, coisas e pessoas" (eficiência), "sujeitos relevantes à justificação" (trabalhadores) e "objetos relevantes à justificação" (emprego, 
empresa e direitos) $)^{23}$. A "eficiência" surge no discurso acima para julgar, aos olhos do agente empresarial, a "ineficiência" da legislação trabalhista que não propicia a celeridade nas relações trabalhistas. A lógica da eficiência atrela-se a existência de um apoio normativo voltado ao mundo industrial cujo princípio superior comum classifica os diferentes seres (agentes e objetos) com base na eficiência. Nesse sentido, a grandeza ou pequenez da legislação trabalhista está atrelada, na mobilização de uma lógica industrial, à sua capacidade de ser eficiente aos propósitos da esfera industrial.

$\mathrm{O}$ discurso do representante da CNA destoa do discurso do representante da CNF e da FEBRABAN na forma em que o emprego é concebido. No caso do representante da CNF e da FEBRABAN, o emprego é observado como um "bem", uma "coisa”, uma "posse", enquanto ao representante da CNA o emprego aparece no discurso como um direito ("o direito ao emprego"). A mobilização do emprego como um direito aponta a um dos objetos que são relevantes ao mundo cívico, isto é, uma cité voltada à representação coletiva. Entretanto, no discurso do agente empresarial, o direito não cumpre a função de representar uma lógica de justificação atrelada ao apoio normativo cívico, e sim sustentar o argumento de que para proteger o emprego, isto é, um direito do trabalhador, é necessário aceitar as condições da reforma trabalhista que, na observação dos representantes do setor empresarial, estão designadas para produzir "ajustes” às relações trabalhistas, como se constata na afirmação "de repente, podemos ajustar uma escala, uma jornada, fazer algo de forma mais eficiente".

$\mathrm{O}$ agente empresarial que representa a $\mathrm{CNT}$, no trecho a seguir, produz um discurso e mobiliza um conjunto de justificações que, simbolicamente, representam uma continuação lógica do discurso destacado nos parágrafos anteriores. Dito isso, uma questão a ser ressaltada na análise é a compreensão do encadeamento lógico das justificações entre diferentes agentes empresariais que, por partirem de apoios normativos semelhantes, produzem uma homologia discursiva que atravessa a todos. O próximo trecho, portanto, pode 23 A apresentação dos descritores durante a exposição da análise funda-se na busca do princípio de transparência do processo de análise, para que eleitores possam compreender de forma mais próxima as decisões operadas pelo pesquisador e, ainda mais, ampliar a possibilidade de discussão dos achados empíricos. 
ser encarado como uma continuação lógica do discurso empresarial acerca da reforma trabalhista.

As normas vigentes são rígidas, demasiadamente protetivas e pouco abertas às negociações de relações de trabalho. Por isso, são eleitas como as principais responsáveis pela estagnação econômica, em virtude do custo excessivo do emprego formal. (...) Para mudar esse cenário, precisamos garantir a geração de empregos e, para isso, é fundamental que a legislação trabalhista seja mais flexível e moderna. Evidentemente, o aumento da atividade econômica depende de diversos fatores, como uma legislação tributária mais justa e eficiente - como eu já havia dito —, melhoria da infraestrutura e redução do déficit fiscal. Porém, o custo do emprego gerado pelas normas trabalhistas vigentes é um entrave para a criação de mais vagas e, inclusive, para a atração de multinacionais. Diversos países são mais atrativos para essas empresas do que o Brasil.

Representante da CNT

O discurso do agente empresarial destacado gira em torno da noção de custo do trabalho. Para justificar o discurso favorável à reforma trabalhista, o agente empresarial mobiliza noções como a "rigidez" das normas vigentes (na qual o uso retórico do termo "rigidez" implicitamente deságua num ângulo específico da observação do agente), sua proteção "em demasia" e baixa abertura à negociação das relações de trabalho. Ocorre um subtexto da "proteção em demasia" que reflete uma insatisfação, da classe empresarial, na forma como a legislação trabalhista aborda a relação entre patrões e trabalhadores. Historicamente, o direito do trabalho surge, ao menos na sociedade brasileira, para lidar com a assimetria de forças constatada na relação entre capital e trabalho ou, especificamente, entre patrões e trabalhadores. $\mathrm{O}$ direito do trabalho existe para resguardar a parte mais frágil nas relações de trabalho que é a classe trabalhadora. Nesse sentido, a legislação trabalhista, mesmo com suas inúmeras modificações de conteúdo durante sua existência, desde a década de 1940, nos momentos anteriores à reforma trabalhista, buscava garantir uma rela- 
ção equilibrada e equivalente entre patrões e trabalhadores. Justificar favoravelmente a reforma trabalhista, por parte dos agentes empresariais, ao classificá-la como rígida reflete a insatisfação dos representantes do setor empresarial em não conseguir negociar com base em ideias econômicas que estimulam a flexibilização dos contratos. Os direitos trabalhistas garantidos pela legislação trabalhista pré-reforma apresentam-se como, aos olhos dos agentes empresariais, como empecilhos que geram custos "excessivos" às empresas.

Dos componentes do conceito de cité destacados a partir do trecho acima, identificam-se três. As relações naturais entre os seres, no discurso, evidenciam a "negociação". A grandeza da reforma trabalhista, portanto, é classificada pelos agentes empresariais com base na sua possibilidade de permitir que as relações entre patrões e trabalhadores seja pautada pela negociação, quanto mais livre for de regulações do Estado, via legislação trabalhista. Os representantes do setor empresarial chegam a essa conclusão a partir de "testes modelo" - que tencionam a grandeza do que se está em disputa - nas suas experiências cotidianas dentro das empresas, e onde as negociações entre trabalhadores e patrões na legislação trabalhista pré-reforma não garantem, para aqueles que mobilizam o apoio normativo mercantil, a livre negociação entre as partes, uma característica presente tanto na esfera mercantil quanto em ideias vinculadas ao pensamento econômico neoclássico, se forem resgatados autores como Adam Smith ou Friedrich Hayek. O julgamento, dos agentes empresariais, sobre a legislação trabalhista pré-reforma, expressase na afirmação de que produz muitos custos trabalhistas a serem arcados pelos empresários e donos de empresas. Frente a essa observação, os representantes do setor empresarial procuram justificar a urgência da reforma trabalhista.

O trecho a seguir se insere na continuidade dos discursos anteriores, apresentando uma lógica de justificação orientada à preocupação da classe empresarial com os custos de trabalho, seja no setor agrícola ou seja no comercial. 
Qual é o Brasil que nós queremos? Seja no comércio, que tem a época de Natal, seja na agricultura, que tem o ciclo de safra, deve se arriscar e empregar ou simplesmente mecanizar, automatizar a operação. É disto que estamos falando, retomada da capacidade econômica, segurança jurídica e investimento. Nós não podemos afastar do cenário internacional o custo trabalhista, que é uma realidade, uma das variáveis importantes. Não adianta, por exemplo, apertarmos nossos pesquisadores, investir em tecnologia, conseguir, Alexandre, ganhar 5\% em inovação tecnológica, se perdemos $10 \%$ em custo trabalhista. Esse não é o Brasil que nós queremos. Nós precisamos enfrentar isso. Querendo ou não, a negociação coletiva é um caminho para isso, Presidente.

Representante da CNA

No discurso acima, nota-se, por um lado, a associação do “emprego" ao "risco" e, por outro lado, a associação entre o "simples" e a "mecanização" do trabalho. O custo do trabalho, pelo encadeamento dos discursos, apresenta uma grandeza maior do que as coletividades no mundo do trabalho, indicando a prevalência de uma lógica atrelada à esfera mercantil, fundamentada na lógica do lucro, custos e benefícios, frente a outros tipos de lógicas de ação e justificação que são voltadas ao mundo cívico, à solidariedade enquanto grandeza. Ao escolherem pelo custo do trabalho em detrimento de outros objetivos, os representantes do setor empresarial deixam em segundo plano o lado solidário da economia e, frente ao apoio normativo cívico, poderiam ser classificados como pequenos.

Os componentes e os descritores destacados pela análise referem-se aos apoios normativos fundados na lógica industrial e mercantil. As relações naturais entre os seres referem-se à negociação, isto é, relações que organizam as associações entre sujeitos e objetos. A negociação coletiva, destacada pelo agente empresarial, procura apontar para futuras relações entre trabalhadores e patrões que sejam pautadas pelo "livre acordo" entre as partes, sem a interferência direta do Estado, tal qual foi definido pela proposta da reforma trabalhista. O componente da forma da evidência voltada ao retorno, 
benefício e resultado é observado na preocupação do representante do setor empresarial ao enfatizar os mecanismos necessários para reduzir o custo do trabalho. A mecanização da produção, no setor agrícola, surge no discurso como uma contraposição ao emprego e um meio para alcançar o objetivo da redução do custo do trabalho. O benefício ou retorno é uma evidência da grandeza ou pequenez de um sujeito ou objeto quando pautado pela lógica mercantil de justificação. Então, a reforma trabalhista surge, no horizonte do discurso do agente empresarial, como uma oportunidade de produção da evidência de que as propostas, se encaminhadas conforme o projeto de lei, trarão um retorno (o benefício) que justifique sua implementação.

O trecho destacado abaixo afasta-se do tema anterior, voltado ao custo do trabalho, e se aproxima do papel do Estado frente ao mercado de trabalho. O representante do setor empresarial argumenta na direção de um cenário em que as negociações e relações de trabalho sejam decididas exclusivamente a partir daqueles diretamente relacionados ao mundo do trabalho, quais sejam, os trabalhadores e os empresários.

Eu quero fazer uma saudação especial aos autores desse projeto, porque, acima de trazer questões objetivas, ele traz uma proposta de mudança do paradigma que veio inscrito na Constituição de 1988 e que nós representantes sindicais - e, quando falo de nós representantes sindicais, estou falando tanto dos representantes das categorias profissionais como dos representantes das categorias econômicas — não tivermos coragem de fazer, que é o exercício pleno da representação e o exercício pleno da liberdade, para que nós possamos chegar àquilo que seria o ideal, que é o princípio da autonomia privada coletiva, ou seja, as partes, as categorias definem aquilo que é importante para elas, e não cabe ao Estado intervir; o Estado cria o ambiente, e nós vivemos e trabalhamos dentro desse ambiente.

Representante da CNC

No discurso destacado, a liberdade e a representação surgem paralelas e conectadas, apontando para uma articulação entre a esfera cívica e a esfera mercantil. O resgate da Constituição funciona, no discurso, 
para apresentar o contexto do argumento do agente empresarial, orientado para justificar a necessidade de que as categorias diretamente relacionadas ao trabalho negociem "livremente" (o "princípio de autonomia privada coletiva") sem que Estado defina o resultado da negociação. A lógica cívica opera, por um lado, ao ser defendido de que as categorias que representam os trabalhadores e as que representam os empresários operem com base naquilo que é defendido pelo objeto cívico, ou seja, a Constituição de 1988. Por outro lado, a lógica de justificação do mercado opera quando se destaca o princípio da autonomia privada coletiva, defendida pelo representante do setor empresarial.

O princípio superior comum mobilizado pelo representante do setor empresarial refere-se ao coletivo e à representação. Operase um estado de grandeza onde o grande é aquele que é representativo, enquanto o Estado surge no discurso como pequeno por não ser representativo tanto aos trabalhadores quanto aos setores patronais. Entretanto, o Estado democrático e representativo surge também do mundo cívico, assim como o discurso operado pelo agente empresarial. Em absoluto, o apoio normativo mercantil interfere na mobilização do discurso plenamente cívico ao direcionar o sentido para a ausência do Estado nas negociações. A esfera cívica é mobilizada, na justificação, para fundamentar favoravelmente uma lógica de mercado que seja pautada pela "livre" negociação no mercado de trabalho. A expressão "mercado de trabalho", por si, sugere um espaço social fundamentado numa lógica mercantil em que a negociação, o contrato, o custo, o benefício e a posse são símbolos do ordenamento dos sujeitos e objetos da esfera mercantil. Portanto, a existência e a mediação do Estado surge, para todos os sujeitos que conferem grandeza àqueles elementos e símbolos, como "fora de seu lugar".

$\mathrm{Na}$ esteira do discurso dos representantes do setor empresarial, se tomado de maneira orgânica, segue a tendência anterior a separar as funções do Estado, definidas via legislação trabalhista pré-reforma e direito do trabalho, em proteger a parte mais frágil das relações trabalhistas. No próximo trecho, destaca-se a contínua justificação de que os trabalhadores e os patrões são os protagonistas das relações que determinam os contratos de trabalho e, de maneira ampla, as relações 
trabalhistas, com o Estado enquanto pano de fundo das negociações, e não incidindo diretamente sobre as relações trabalhistas.

Hoje, para defender o trabalhador, temos Ministério Público, Justiça do Trabalho, auditoria fiscal, centrais sindicais, sindicatos, advogados do mais alto escalão, como disse aqui Cristiano. E, para defender o empresário, quem nós temos? Querem saber quem? O trabalhador. Porque na verdade quem gera riqueza no Brasil é só trabalhador e empresário. Desculpem eu ter que dizer isso para os senhores, mas Ministério Público não gera riqueza, Executivo não gera riqueza, Legislativo não gera riqueza, Judiciário não gera riqueza. Se nós destruirmos a capacidade que os geradores de riqueza têm de autonomamente decidirem o que é melhor para si, num Brasil tão heterogêneo, com tantas especificidades, estaremos matando a capacidade de termos efetivamente um País de primeiro mundo.

Representante da CNI

No discurso, o representante do setor empresarial busca afastar a figura do Estado do cenário das negociações trabalhistas. A justificação se fundamenta no argumento de que apenas quem gera riqueza deve negociar as formas nas quais a riqueza é gerada e compartilhada. Nesse caso, tem-se um objeto do mundo mercantil ("riqueza"), o qual pertence a todo um conjunto simbólico e material marcado pelas relações de mercado. No discurso destacado, o grande é aquele que gera riqueza material, enquanto o pequeno é aquele que não gera riqueza. Os grandes, portando, são definidos como os trabalhadores e os empresários, pois geram riqueza, enquanto o Estado surge como pequeno. A classificação dos seres é operada por meio de uma ótica de justificação pautada pela esfera mercantil, atuante no mundo do trabalho e sendo manifestada pelos agentes empresariais nas audiências públicas. Simultaneamente, "não produzir" riqueza atende à lógica industrial da "produção". O grande, no apoio normativo industrial, é aquele que produz e é produtivo, enquanto o que não produz, que é improdutivo, é pequeno. Portanto, ocorre uma articulação de apoios normativos para justificar que são 
os produtores de riqueza que devem negociar as condições das relações trabalhistas e não os "improdutivos". A riqueza, por fim, tornase um objeto relevante à justificação favorável à reforma trabalhista.

No trecho a seguir, o representante do setor empresarial argumenta que, atualmente, é mais importante proteger o emprego do que o trabalhador, e para tal, é necessário amparar a empresa, pois é quem gera empregos. Se o direito do trabalho historicamente fora produzido para proteger a parte mais vulnerável das relações trabalhistas, a proposta do agente empresarial é inverter essa proteção e orientar a lógica da legislação trabalhista para proteger a classe empresarial.

As relações de trabalho no mundo moderno são diferentes das relações de trabalho nos anos 40, época em que foi criada a Consolidação das Leis do Trabalho. Hoje em dia, mais importante do que a proteção do trabalhador é a proteção do emprego, e, para protegê-lo, é necessário proteger a empresa e estimular a geração de empregos por parte do empregador também.

Representante da CNT

Quando se resgatam discursos anteriores, na busca de um discurso relativamente representativo do conjunto dos representantes do setor empresarial, nota-se um encadeamento do custo do trabalho com a proteção do emprego. Para reduzir os custos das empresas com o trabalho, é inescapável, aos olhos dos agentes empresariais, proteger o emprego e, por consequência, a quem gera empregos, a empresa, isto é, o setor empresarial. Proteger o emprego significaria, dentro da lógica apresentada, evitar demissões em massa e reduzir os custos do trabalho. Implicitamente, o discurso dos representantes do setor empresarial encadeia uma lógica mercantil que defende a redução de custos do trabalho, a partir de uma legislação trabalhista que proteja "o emprego". Dentro dessa lógica, "proteger o emprego" significaria afastar a proteção do Estado em relação ao lado frágil da negociação, retirando um conjunto histórico de regras e normativas protetivas ao trabalhador, inscritas na CLT. 
No último trecho apresentado neste artigo, pretende-se destacar sinteticamente os elementos inscritos nos apoios normativos mobilizados pelos representantes do setor empresarial. Abaixo, temse um trecho orientado para "negociação de direitos".

Em hipótese alguma aqui se fala, ou se comenta, ou se trabalha com a ideia de redução dos direitos, mas com a ideia de fazer com que esses direitos, que são conquistas dos trabalhadores, sejam usufruídos, sejam decididos, sejam negociados, porque ele especificamente sabe o que é melhor para a sua atividade, assim como a empresa. Representante da CNS

O discurso mobilizado pelo agente empresarial busca justificar a reforma trabalhista ao argumentar que os trabalhadores devem "ser livres" para negociar o que é melhor para si mesmos, assim como as empresas. A figura do Estado deve ser afastada da negociação, tornando apenas os diretamente associados ao mundo o trabalho, aos olhos do agente empresarial, como responsáveis pelo seu próprio destino. A "negociação", "negociar" e "direitos" são elementos constitutivos do discurso do agente empresarial. A negociação e a ação de negociar são elementos próprios do apoio normativo mercantil. O grande no mundo mercantil é aquele que negocia livremente sem a interferência de qualquer entidade considerada pelo observador como externa à negociação. A noção de "direitos" surge no discurso como um objeto do argumento cuja lógica mercantil incide sobre, destituindo o conceito cívico do "direito" como uma garantia constitucional, que advém da esfera cívica, para adaptá-la aos termos do mundo mercantil, transformando-a num "bem", numa "coisa" ou "posse", que pode ser negociada. A justificação nessa direção torna-se clara ao destacar a frase "fazer com que esses direitos, que são conquistas dos trabalhadores, sejam usufruídos, sejam decididos, sejam negociados". Junto dos trechos anteriores, destaca-se como as justificações dos representantes do setor empresarial apresentam aproximações discursivas e normativas muito próximas de uma lógica mercantil. 
As justificações, tomadas como um todo, mobilizadas pelos representantes do setor empresarial funcionam em seus respectivos discursos para legitimar e naturalizar socialmente a necessidade de efetivar o conteúdo e os propósitos da reforma trabalhista. A próxima sessão, destinada às notas conclusivas do artigo, encarrega-se do fechamento do argumento do artigo.

\section{NOTAS CONCLUSIVAS}

A reforma trabalhista foi produto de um cenário político e econômico brasileiro institucionalmente instável. Em virtude da reorganização das forças sociais favoravelmente interessadas na reforma trabalhista, tornou-se possível avançar com um conjunto de propostas que incorporam uma ideologia alinhada aos interesses da classe empresarial brasileira. Evidências foram apresentadas no sentido de demonstrar sociologicamente quais os modelos de justiça implícitos nas justificações mobilizadas pelos representantes do setor empresarial brasileiro.

Buscou-se examinar as justificações favoráveis à reforma trabalhista a partir da análise dos discursos mobilizados pelos representantes do setor empresarial, numa audiência pública organizada pelo Congresso Nacional. Os principais elementos resgatados pelos agentes empresariais foram o custo do trabalho, a "rigidez" da legislação trabalhista pré-reforma, a "livre" negociação entre as partes diretamente envolvidas pelas relações trabalhistas, $i$. e., os trabalhadores e os empresários, sem a interferência do Estado e com a flexibilização do contrato de trabalho.

Apesar da heterogeneidade de interesses da classe empresarial, no sentido material e econômico, os representantes desse setor empresarial mobilizaram-se, nas audiências públicas, numa espontaneidade orgânica que unificou seus interesses na mesma direção: o apoio à reforma trabalhista. Igualmente, suas justificações apresentaram uma orientação de síntese, voltadas, principalmente, à lógica mercantil, isto é, ao modelo de justiça que encarna uma cité mercantil, orientada ao lucro, à redução de custos, aos resultados, aos benefícios, à livre 
circulação de mercadorias e à posse de bens valiosos. Secundariamente, os representantes do setor empresarial mobilizaram um apoio normativo orientado pela cité industrial, onde a primazia de classificação do mundo social se funda na eficiência, produtividade, investimento e mecanização. Timidamente, os representantes mobilizaram o apoio normativo da cité cívica que, quando mobilizada, funcionava para fortalecer os argumentos centrados na cité mercantil.

Os discursos se orientaram, em parte, à justificação mercantil do emprego como um "bem", uma "posse" e não como um direito. Os agentes empresariais classificaram as propostas da reforma trabalhista com base na ótica mercantil, que regula as observações na direção de bens e posses. Ao não observarem o emprego como um direito, identifica-se a não adoção de um modelo de justiça fundado numa cité cívica, na qual o princípio superior comum é o coletivo e a vontade geral e onde um dos objetos pertencentes a esse mundo cívico manifesta-se exatamente na noção de direitos.

As justificações analisadas funcionam para naturalizar e legitimar um conjunto de ideias econômicas - que historicamente encontram ressonância nas obras de Adam Smith, David Ricardo, Friedrich Hayek e Milton Friedman - orientadas à "flexibilização" dos contratos de trabalho, à redução dos custos trabalhistas, ao aumento da autonomia privada coletiva e, consequentemente, ao afastamento do Estado de matérias na intermediação das relações entre a classe trabalhadora e a classe empresarial. $\mathrm{O}$ teor das propostas acaba pendendo unilateralmente a atender os interesses da classe empresarial, representados nas seguintes organizações: CNI, CNT, CNF, FEBRABAN, CNA, CNS e CNC.

As justificações mobilizadas por esse grupo de representantes do setor empresarial funcionaram para mascarar seus interesses - pela função de legitimação e naturalização daquelas - ao empregar um conjunto de discursos políticos direcionados a temas que dificilmente encontram opositores (discursivamente, quais agentes seriam contra investimentos, geração de empregos ou liberdade?). Entretanto, resgatando a identificação dos modelos de justiça operados pelos representantes do setor empresarial, constata-se que as 
propostas da reforma trabalhista contemplam apenas aqueles que compartilham dos mesmos apoios normativos..

O conceito de cités mostrou-se frutífero, reflexivo e compreensivo a ponto de permitir a produção de um entendimento da legislação trabalhista quando pensado à realidade brasileira. Entretanto, destaca-se a necessidade da continuidade, no exercício sociológico e intelectual, em contrastar os conceitos teóricos em outras formações sociais, para testar seu valor heurístico e explicativo. Ao empregar uma intenção sociológica que busca constantemente o contraste de realidades, a teoria sociológica tem a ganhar conceitos que não são mônadas, isto é, conceitos fechados e imutáveis, e sim ferramentas que possibilitam novas reflexões e, especialmente, interrogações que apoiam avanços científicos em direções inesperadas e inescapáveis. Dito isso, os conceitos sociológicos não são tecnologias em que se importam de uma sociedade a outra, mas que precisam atender à história da formação sociocultural de cada sociedade, enriquecendo-se à medida que são testados, sendo corroborados ou refutados. Portanto, novos estudos precisam ser realizados para avançar-se na compreensão dos modelos de justiça, definidos nas cités, que contemplem plenamente os dilemas, as continuidades e as rupturas com a formação social brasileira.

A função social da Sociologia e da teoria sociológica, por fim, enriquecem-se ao desvendar discursos dados como verdadeiros, ou seja, justificações naturalizadas quando apresentadas ao público sem a devida reflexão e exame intelectual. Ao encarar os dados à luz da inescapável presença e vivência em sociedade, tanto na relação com os objetos de estudo quanto com os pesquisadores, têm-se a corroboração do valor heurístico que a sociologia proporciona e que transborda suas fronteiras. 


\section{REFERÊNCIAS}

ALMEIDA, M. Análise de dados na pesquisa qualitativa: Desafios ao pensamento criativo. Arxius de Ciêncies Socials, vol. s/i, no 31, pp. 143-153, 2014.

ANNER, M. Meeting the challenges of industrial restructuring: labor reform and enforcement in Latin America. Latin American Politics and Society, vol. 50, $\mathrm{n}^{\mathrm{o}}$ 2, pp. 33-65, 2008.

ANTUNES, P.; CARVALHOS, P. A trajetória do sindicalismo: uma análise da história, conceitos e perspectivas sindicais. Campinas: Editora Alínea, 2008.

ARMELINO, M. El proceso político de la reforma laboral em la administración pública argentina (1989-1999). Trabajo y Sociedad, vol. s/i, n 24, pp. 29-52, 2015.

BOLTANSKI, L.; CHIAPELLO, È. O novo espirito do capitalismo. São Paulo: Editora WMF Martins Fontes, 2009.

BOLTANSKI, L.; THEVENOT, L. On justification: economies of worth. Princeton: Princeton University Press, 2006.

BURGESS, K. Global pressures, national policies, and labor rights in Latin America. Studies in Comparative International Developent, vol. 45, no 2, pp. 198-224, 2010.

CARDOSO, A.; LAGE, T. Desenho legal e desempenho real: Brasil. In: BENSUSÁN, G. Instituições trabalhistas na América Latina: desenho legal e desempenho real. Rio de Janeiro: Revan, 2006, pp. 161-224.

CASTEL, R. As metamorfoses da questão social: uma crônica do salário. Petrópolis: Vozes, 1998.

CASTRO, Nadya. A máquina e o equilibrista. Rio de Janeiro: Paz e Terra, 1995.

CHIAPELLO, È. Reconciling the two principal meanings of the notion of ideology: the example of the concept of the 'Spirit of Capitalism'. European Journal of Social Theory, vol. 6, n 2, pp. 155-171, 2003.

COOK, M. Labor reform and dual transitions in Brazil and the Southern Cone. Latin American Politics and Society, vol. 44, n 1, pp. 1-34, 2002.

COOK, M. Toward flexible industrial relations? Neo-liberalism, democracy, and labor reform in Latin America. Industrial Relations, vol. 37, $\mathrm{n}^{\circ}$ 3, pp. 311-336, 1998.

DINIZ, S. Interações entre os Poderes Executivo e Legislativo no processo decisório: avaliando sucesso e fracasso presidencial. Dados - 
Revista de Ciências Sociais, vol. 48, nº 1, p. 333-369, 2005.

GALVÃO, A. Neoliberalismo e reforma trabalhista no Brasil. 2003. 406 p. Tese (Doutorado em Ciências Sociais) Programa de Pós-Graduação em Ciências Sociais, Universidade Estadual de Campinas, Campinas, SP.

GIBBONS, S. La experiencia neoliberal. Privatización de servicios públicos y reforma laboral en perspectiva neoinstitucionalista, 1989-1996. Temasy debates, vol. 30, n 19, pp. 87-107, 2015.

GOLDÍN, A. Reforma y contrarreforma laboral em Argentina, crónica simple de um processo pendular. Derecho PUCP, vol. s/i, no 68, pp. 63-92, 2012.

HAAGH, L. The Emperor's new clothes: labor reform and social democratization in Chile. Studies in Comparative International Development, vol. 37, $\mathrm{n}^{\circ}$ 1, pp. 86-115, 2002.

IBGE. In: https://www.ibge.gov.br/estatisticas-novoportal/sociais/ trabalho/17270-pnad-continua.html? $=\& \mathrm{t}=$ series-historicas, acesso em 26 de junho de 2018.

KAPLAN, D. Job creation and labor reform in Latin America. Journal of Comparative Economics, vol. 37, nº 1, pp. 91-105, 2009.

LOVE, J. Ideias e ideologias econômicas na América Latina, c. 1930-1990. In: BETHELL, L. História da América Latina: América Latina Colonial, vol. 8. São Paulo: EDUSP; Brasília: Fundação Alexandre de Gusmão, 2011, pp. 161-242.

MARX, K. As lutas de classes na França de 1848 a 1850. São Paulo: Boitempo, 2012.

MAYER, J. The limits of labor legislation reforms: rigidity, growth, and employment in Brazil (1995-2010). Journal of Politics in Latin America, vol. 8, n 1, pp. 95-127, 2016.

MORRIS, R. Labor reform in the australian merchant marine: na analysis of recente progress. Transportation Journal, vol. 33, n 44, pp. 43$50,1994$.

MOYA, M. Executivo versus Legislativo: os vetos presidenciais no Brasil (1988-2000). 2005. 170 p. Tese (Doutorado em Ciência Política) Programa de Pós-Graduação em Ciência Política, Universidade de São Paulo, São Paulo.

OJEDA, A.; GUTIÉRREZ, M. La reforma del mercado de trabajo en España durante la crisis financieira internacional. Derecho PUCP, vol. s/i, no 68, pp. 93-129, 2012.

ROXBOROUGH, I. A classe trabalhadora urbana e o movimento trabalhista na América Latina após 1930. In: BETHELL, L. História da América Latina: América Latina Colonial, vol. 8. São Paulo: EDUSP, Brasília: Fundação Alexandre de Gusmão, 2011, pp. 275- 
353.

PESSANHA, E. ARTUR, K. Direitos trabalhistas e organização dos trabalhadores num contexto de mudanças no mundo do trabalho: efeitos sobre os trabalhadores da saúde. Ciência \& Saúde Coletiva, vol. 18, nº 6 , pp. 1569-1580, 2013.

PINTO, C. Elementos para uma análise de discurso político. Barbarói (online), vol. s/i, no 24, pp. 78-109, 2006.

SANTOS, B.; FERREIRA, B. Cidadão. In: JÚNIOR, J. Léxico da história dos conceitos politicos do Brasil. Belo Horizonte: Editora UFMG, 2014, pp. 41-58.

SEMPERE, A. Legislación de emergencia y reforma laboral en España (2011-2012). Derecho PUCP, vol. s/i, nº 68, p. 157-192, 2012.

TAYLOR, M. Labor reform and the contradictions of 'growth with equity' in postdictatorship Chile. Latin American Perspectives, vol. 31, $\mathrm{n}^{\mathbf{0}}$ 4, pp. 76-93, 2004.

TOSTES, M.; VILLAVICENCIO, A. Flexibilización del Drecho del Trabajo y sus implicancias sobre las relaciones laborales en el Perú. Derecho PUCP, vol. s/i, nº 68, pp. 355-382, 2012.

WANDERLEY, L. A questão social no contexto da globalização: o caso latino-americano e o caribenho. In: BELFIORE-WANDERLEY, M.; BÓGUS, L.; YAZBEK, M. Desigualdade e a questão social. São Paulo: EDUC, 2013, pp. 61-172 